\title{
ANALISIS ISI PESAN DAKWAH PADA RUBRIK DIALOG JUM’AT KORAN LOMBOK POST
}

\author{
Rina Fitriani \\ Email: rinafitriany8@gmail.com
}

\begin{abstract}
The Friday dialogue rubric is published so that there is a balance between general studies and religion, not only providinggeneralinformationbutalso descriptiveinformation about the Islamic religion. And it must be acknowledged that knowledge about religion, especially those relating to daily life, is needed by the community, especially the Muslim community in NTB. With the existence of print media, it will be easier to access and obtain information about a matter contained in the missionary message. The role of da'wah in the print media prioritizes the interests of the reader, strives to increase intelligence and welfare through information. Newspapers as Media Da'wah are the media and mouthpieces of the nation's progress. This paper will focus on the discussion of the analysis of the contents of the da'wah message at the Lombok Post Newspaper in the Friday Dialogue Edition of the August 2017 Edition.
\end{abstract}

Keywords: Message, Rubric, Discourse Analysis 


\begin{abstract}
Abstrak
Rubrik dialog Jum'at di terbitkan supaya ada keseimbangan antara kajian umum dan agama, tidak hanya memberikan informasi umum tetapi juga memerikan informasi seputar agama Islam. Dan harus di akui pengetahuan tentang agama terutama yang berkaitan dengan kehidupan sehari- hari sangat di butuhkan oleh masyrakat terutama masyrakat muslim di NTB. Dengan adanya media cetak, akan lebih mudah mengakses dan memperoleh informasi akan suatu hal yang terkandung dalam pesan dakwah. Peran dakwah di media cetak mengutamakan kepentingan pembaca, mengusahakan peningkatan kecerdasan dan kesejahteraan melalui informasi. Surat Kabar Sebagai Media Dakwah menjadi media dan corong kemajuan bangsa. Paper ini akan fokus pada pembahasan tentang analisis isi pesan dakwah pada Koran Lombok Postdalam Rubrik Dialog Jumat Edisi Bulan Agustus Tahun 2017.
\end{abstract}

Kata Kunci: Pesan, Rubrik, Analisis Wacana

\section{A. Pendahuluan}

Islam merupakan agama dakwah, artinya agama yang selalu mendorong umatnya untuk berbuat kebaikan dan mengajak orang lain agar menjadi insan yang baik. Implikasi dari pernyataan tersebut mewajibkan bagi setiap umat Islam untuk melakukan aktivitas dakwah.Hukum berdakwah adalah wajib bagi sebagian orang yang memang memiliki pengetahuan dan pemahaman dalam masalah agama.Di zaman sekarang ini dakwahbil qalamatau melalui media cetak lebih efektif, mengingat tidak selamanya pembacabisa mengikuti pengajian atau pun majelis taklim. Tidak bisa dipungkiri, kebanyakan pembaca sibuk dengan pekerjaan dan aktivitasnya, sehingga ia tidak bisa untuk menghadiri pengajian.

Dengan adanya media cetak,akan lebih mudah mengakses dan memperoleh informasi akan suatu hal yang terkandung dalam pesan dakwah.Peran dakwah di media cetak mengutamakankepentingan pe mbaca, mengus a hakan peningkatan kecerdasan dan kesejahteraan melalui informasi, harus mampuSurat Kabar Sebagai Media Dakwah menjadi media dan corong kemjuan bangsa. 
Pemanfaatansurat kabar sebagai media dakwah dimaksudkan bukan untuk mengganti peranan dakwah billisan maupun dakwah bilhal tetapi tetap dalam konteks dakwah, penyampaian misi dakwah melalui surat kabar adalah sebagai sarana Islamisasi kehidupan. Dan Kelebihan surat kabar dibanding media lainnya adalah biayanya murah isinya dapat dibacaberulangulang, bertahan lama dan dapat dikoreksi kembali bila terdapat kesalahan ataupenyimpangan dalam penyajiannya, sehingga diharapkan dakwah dapat tersiar danterpublikasi pada khalayak dengan baik dan benar. Bahkanmediacetakbisamenentukan perkembangan masyarakat seperti apa yang akan dibentuk di masa yang akan datang.Pada dasarnya Di NTB terdapat sekurang-kurangnya 161 hingga tahun 2016 yang meliputi media cetak yang saat ini berkembangan dengan sangat pesat dan dinilai dalam kondisi baik, dan bahkan di perkirakan bisa bertambah jelang pilkada serentak 2018-2019 mendatang.

Media cetak mampu mengarahkan, membimbing, dan memengaruhi kehidupan di masa kini dan masa datang. Terkait dengan itu tidak sedikitpun media cetak yang mulai mengarahkan Orientasi beritanya ke arah misi dakwah seperti salah satu media cetak yang tedapat di Nusa Tenggara Barat, yaitu lombok post yang merupakan sebuah koran harian pagi pertama dan terbesar di NTB yang salah satunya berlandaskan religius nasionalis, dan koran ini termasuk dalam group jawa pos. Yang kantor pusatnya tereletak di kota Mataram dan pertama kali terbit pada tahun 1991. Koran Lombok Post terdapat 10 kolam diantaranya Berita, Nasional, Sportivo, Pelesir Lifestle Tecno, Otoholic opini, Rubrik, dan Feacture.

Dari 10 halaman terdapat salah satu Rubrik yang berisikan tajuk keagamaan dan pesan-pesan keagamaan yang diisi setiap harinya oleh TGH. Safwan Hakim dalam kolomtersebutbeliaumenyampaikan Dakwah- Dakwahnya, Tetapi tidak banyak dari media cetak yang menyediakan kolom khusus untuk mengisi atau menyampaikan sesuatu yang menyangkut tentang keagamaan seperti di Koran Lombok Post yang memiliki kolom khusus bertajuk keagamaan yaitu Dialog Jum'at dan diterbitkan setiap hari Jum'at, dan mampu bertahan hingga sekarang dikarenakan permintaan dari para pembaca agar Dialog Jum'at tersebut bisa dan tetap disajikan di koran tersebut. 


\section{B. Media}

a. Pengertian Media

Media adalah salah satu alat yang dipergunakan untuk menyampaikan materi dakwah kepada mad'u. Pada zaman modern seperti sekarang ini, seperti televisi, video, kaset rekaman, majalah dan surat kabar.Media adalah segala sesuatu yang dapat dijadikan sebagai alat perantara untuk mencapai satu tujuan tertentu. Sedangkan dakwah adalah segala sesuatu yang dapat dipergunakan sebagai alat untuk mencapai tujuan dakwahyang telah ditentukan, media dakwah ini dapat berupa barang atau alat, orang, tempat, kondisi tertentu dan sebagainya. ${ }^{1}$

Fakta-fakta hasil persepsi dan observasi, berupa "rekaman" peristiwa merupakan realitas yang selanjutnya akan disusun dan ditulis menjadi berita. Dengan demikian berita merupakan hasil konstruksi realitas dalam bentuk wacana bermakna. $^{2}$

Berangkat dari gambaran surat kabar berdakwah melalui koran perlu ditata teknik yang tepat dan peningkatanisi/materidakwahsesuai dengan kebutuhan masyarakat yang

1 K Khurin>in,"media sebagai alat dakwah”, dalam digilib.uinsby.ac.id.bab\%202. pdf, 2013 diakses ( tanggal 17 januari 2018 , pukul 10,53)

2 Mursito BM, Jurnalistik Komprehensif, (Jakarta: Literate, 2013), 70-71. berarti bahwa berdakwah melalui tulisan di koran membutuhkan tulisan yang selektif dan terarah untuk masyarakat luas. Oleh karena itu menulis pesan-pesan dakwah di koran perlu memperhatikan karakteristik media massa.

Asep Saiful Muhtadi dalam bukunya Jurnalistik Pendekatan Teori dan Praktek mengemukakan karakteristik media massa sebagai berikut, pertama, komunikasi massa berlangsung satu arah. Kedua, komunikasinya bersifat melembaga. Ketiga,pesan-pesanyangdisampaikan bersifat umum. Keempat, pesanpesan yang disampaikan lewat media digunakan secara serempak. Kelima, komunikasinya bersifat heterogen. ${ }^{3}$

Dengan demikian berdakwah melalui surat kabar harus selalu memperhatikan prinsip-prinsip komunikasi pada umumnya. Selama ini, penulis berita selalu berpegang pada enam pedoman dalam menulis suatu berita yaitu: apa yang terjadi, siapa yang terlibat di dalamnya, mengapa kejadian atau peristiwa itu terjadi, dimana terjadinya, kapan peristiwa itu terjadi, dan bagaimana kejadiannya. Khusus untuk tujuan komunikasi massa seperti dakwah bagi masyarakat luas maka produk

3 Jurnal Altajdid, Surat Kabar Sebagai Media Dakwah(Stain Palopo, 23 April 2018). 
jurnalistik dapat disampaikan melalui media. ${ }^{4}$

\section{Teori Agenda Setting}

Hubungan yang kuat antara berita dan yang di sampakan media dengan isu-isu yang di nilai penting oleh publik merupakan salah satu jenis efek media massa yang paling populer yang di namakan Agenda Setting di ciptakan oleh Maxwell McCombs dan Donal Shaw. ${ }^{5}$

\section{Analisis Wacana}

Wacana adalah segala sesuatu yang berbentuk tulisan, perkataan, atau ucapan yang bersifat kontekstual. ${ }^{6}$ Wacana juga dapat diartikan sebagai kumpulan kalimat yang saling berangkai membentuk suatu kesatuan makna yang padu dan utuh. Dalam strata kebahasaan, wacana ditempatkan pada posisi teratas, karenawacana merupakan satuan gramatikal tertinggi dan terbesar di dalam sebuah bahasa. ${ }^{7}$

Wacana dapat berbentuk kata, kalimat, paragraf atau bahkan karanganutuh yangmemilikiamanat lengkap seperti pada buku atau pun artikel. Kalimat - kalimat yang

4 Ibid,,,.

5 Morisson, Teori Komunikasi Individu Hingga Massa, (Jakarta, 2013), 496-297.

6 Nurudin, Jurnalisme Masa Kini, (Jakarta: Rajawali Pers, 2009).

7 Ikram Maifandi, Analisi Wacana dalam di akses pada tanggal 19 april 2018 pada pukul 20.13 . menyusun sebuah wacana haruslah kalimat yang padu dan sesuai dengan konteks, bukan kalimat kalimat yang saling terputus dan lepas konteks. Oleh karena itu, wacana dapat diartikan juga sebagai tulisan atau perkataan yang memiliki keutuhan unsur - unsur makna dan konteks yang melingkupinya. ${ }^{8}$

Analisis Wacana atau Discourse analysis metode untuk mengkaji wacana atau discourse yang ada atau terkandung dalam pesanpesan komunikasi baik itu secara tekstual ataupun kontekstual dan Analisis wacana berkenaan dengan isi pesan komunikasi yang sebagian diantaranya berupa teks, naskah pidato. ${ }^{9}$ Analisis wacana adalah analisis isi yang lebih bersifat kualitatif dan dapat menjadi salah satu alternatif untuk melengkapi dan menutupi kelemahan dari analisis isi kuantitatif yang selama ini banyak digunakan oleh para peneliti. Jika pada analisis kuantitatif, pertanyaan lebih ditekankan untuk menjawab "apa" (what) dari pesan atau teks komunikasi, pada analisis wacana lebih difokuskan untuk melihat pada "bagaimana" (how), yaitu bagaimana isi teks berita dan juga bagaimana pesan itu disampaikan.

8 Ibid, ,.

9 Si Manis, Analis Wacana dalam http:// www.pelajaran.co.idldi akses pada tanggal 19 april 2018 pada pukul 17.16. 


\section{Teori Analisis wacana kritis}

Analisis wacana kritis di definisikan sebagai upaya untuk menjelaskn suatu teks pada fenomena sosial untuk mengetahui kepentingan yang termuat didalamnya. ${ }^{10}$ Analisis Wacana kritis studi tentang teks, ujaran atau bicara, dan gambar-gambar visual untuk mengungkapkan berbagai makna dan analaisis wacana kritis dapat dapat menganalisis diantaranya politik, ras, gender, kelas soial, hegomoni dan lain-lain. ${ }^{11}$

Karakteristik Analisis wacana krirtik yaitu lebih menekankan pada pemahamanteksyangmengandalkan interprestasi dan penafsiran peneliti. Setiap teks di maknai secara berbeda dan di tafsirkan secara beragam. Berprentasi memfokuskan pada pesan latent(tersembunyi) makna suatu pesan tidak bisa hanya di tafsirkan sebagai apa tampak dalm teks, namun harus di analisis dari makna yang tersembunyi.Tujuan menggali bagaimana pemakaian bahsa dalam tuturan atau tulisan

10 Linguistik id, Penegertian Analisi Wacana Kritisdalam http://linguistikid. com,pengertian, diakses pada tanggal 24 april 2018 pukul 20.26

11 Ambar, Analisis Wacana Kritis, Pendekatan Konsep dalam http:// pakarkomunikasi.com dia kses pada tanggal 24 april2018 pukul 20.34 sebagai bentuk sosial termasuk dalamnya praktik sosial. ${ }^{12}$

Van Dijk melihat suatu teks terdiri atas beberapa strukur atau tingakatan yang masing- masing bagian saling mendukung. Ia membaginya ke dalam 3 tingakatan. Pertama , struktur makro. Ini merupakan makna global atau umum dari suatu teks yang dapat di amati dengan melihat topik atau tema yang kedepankan dalm suatu berita. Kedua, superstruktur. Ini merupakan sturktur wacana yang berhubungan dengan kerangka sutu teks, bagaimana bagian -bagian teks tersusun ke dalam berita secara utuh. Ketiga , struktur mikro adalah makna wacana yang di amati dari bagian kecil darinsuatu teks yakni kata, kalimat proposisi, anak kalimat, paraprase dan gambar. ${ }^{13}$

\section{Rubrik DialogJum'at Pada Koran} Lombok Post

Rubrik dialog Jum'at adalah salah satu kolom yang ada di lombok post yang di terbitkan pertama kali pada tahun 1996 pada saat setelah nama lombok post di ganti yang awalnya

12 Zikri Fachrul Nurhadi, Teori-Teori KomunikasiDalam Perspektif Penelitian Kualitatif,(Bogor :Ghalia indonesia ,2015), 83.

13 http://id.m.wikipedia.org,analisi wacana kritis diakses pada tangga 24 april 2018 pukul 20.37 . 
bernama koran Suara Nusa, Yang disepakati Bersama oleh Dewan Redaksi Seperti yang di jelaskan oleh PakJoni Marthadinata selaku sebagai Pimpinan Redaksi mengatakan:

"Dari waktu ke waktu, tahun berganti tahun, Lombok Post terus berkembang. Selain penampilan (perwajahan) yang mengikuti selera pasar dan perkembangan zaman, semakin banyak rubrik yang disajikan. Salahsatunya RubrikDialogJumat yang disajikan di halaman utama (halaman 1) seminggu sekali, setiap hari Jumat.Rubrik Dialog Jumat kali pertama diterbitkan sekitar 1996, setelah Koran Pertama dan Terbesar di NTB ini resmi berganti nama menjadi Lombok Post (sebelumnya Suara Nusa). Rubrik Dialog Jumat merupakan buah pemikiran bersama dewan redaksi, untuk memberikan sajian informatif dan edukatif, khususnya tentang ajaran Islam. Apalagi seperti kita ketahui, Provinsi NTB yang menjadi market utama Lombok Post berpenduduk mayoritas muslim. ${ }^{14}$

Kemudian di jelaskan lagi oleh Pak H. Hamaluddin selaku menjabat

14 Pak Joni Marthadinata Dewan Redaksi Lombok Post(Wawancara Tanggal 15 Mei 2018). sebagai wartawan senior yang mengatakan :

"Nah jadi dulu ini kenapa ada dialog Jum'at ketika itu sekitar tahun 2008 , karena dulu sistem pemerintahan kita masihdalam masa reformasi, ketika itu presiden Suharto di Jakatra berimbas ke daerah beritanya kaitannya dengan aksi-aksi barat kriminal barat pada waktu itu kan jadinya semua pembritaan media termasuk lombok post ketika itu pokus pada kriminal hukum dan poiltik saat itu, nah untuk menyeimbangkannya karena kita adalah daerah seribu masjid akhirnya ada. Untuk mengisikeseimbangan pemberitaan jangan hanya sifatnya prontal tapi media penyejukan medianya juga perlu.Ketika itu kesepakatan tim redaksi waktu mengambil sikap melalui rapat redaksi kalau gak salah waktu itu akhirnya di adakan dialog Jum'at dan kontennya ya itu, pesan-pesan kepada masyarakat yang lagi boming di masayrakat aat itu dan ada kaitannya dengan khutbah-khutabah setiap Jum'at isinya juga macam-macam dah kontentnya yang berterkait dengan dakwah yang artinya untuk memberikan kesejukan moral terhadap masyarakat , 
dan sekitar 2008 itu akhirnya berlanjut- berlanjut dan itu tujuannya dialog jummat itu termasuk lah salah satu visi dan misinyalah. yang punya ide itu $\mathrm{H}$. Munawarun namanya, beliau yang punya ide pertama yang kasih nama khutbah mimbar, dulu namanaya khutbah Jum'at tapi di ganti lagi dengan Dialog Jum'at, Iya pada saat itu yang petama kali isi rubrik itu saya lupa tapi yang jelas waktu itu bukan hanya tuan guru Safwan Hakim yang isi tetapi juga dari tokohtokoh agama yang memang sudah terkenal di kalanagan masyarakat. ${ }^{15}$

Dalalm Hal ini juga di jelaskan oleh mbak Bq. Ida selaku Sekertaris Redaksi mengatakan :

"Jadi Rubrik atau kolom dialog Jum'at itu awalnya di cetuskan oleh tim redaksi pada tahun 2008 sehingga di sepakati oleh semua crew redaksi saat yang hadir di rapat. ${ }^{16}$

Dalam pembuatan Rubrik dialog Jum'at tersbut selagu untuk memberikan kesejukan moral terhadap masyarakat tetapi

15 Pak Hamaluddin Wartawan Senior Lombok Post(Wawancara Tanggal 13 Mei 2018).

16 Mbak Ida sekertaris Redaksi (Wawancara Tanggal 14 Mei 2018). bertujuan untuk menyeimbangkan antara bacaan-bacaan umum dan bacaan-bacaan Islam. Seperti yang di jelaskan oleh Pak Ahmad Ikhliluddin selaku wartawan senior mengatakan:

“ Tujuannya yang jelas sih agar ada ruang untuk pembaca yang ingin tau tentang topik-topik Islam, kemudian hari Jum'at juga kan hari untuk beribadah dan akhirnya di falisitasi rubrik khusus dialog Jum'at.Jadi sebenarnya untuk keseimbangan bacaan-bacaan umum, beritaberita umum dan ada topiknya mengenai agama." ${ }^{17}$

Berbeda halnya dengan pak Joni Marthadinata yang mengatakan bahwa dialog Jum'at sangat di tuggu-tuggu oleh pembaca karena dialog Jum'at adalh salah satu dapat di dapatkan di Koran Lombok Post :

"Seperti disebutkan pada point pertama, penduduk Provinsi NTB mayoritas beragama Islam. Dan harus diakui, pengetahuan tentang agama, terutama yang berkaitan dengan kehidupan sehari-hari sangat dibutuhkan. Nah, pengetahuan itu salah satunya bisa didapatkan melalui

17 pak Ikhliluddin Wartawan Senior (Wawancara Tanggal 17 Mei 2018). 
Rubrik Dialog Jumat yang disajikan Lombok Post. Dari sisi bisnis, Rubrik Dialog Jumat merupakan salah satu "alat" untuk mengikat pembaca setia atau pelanggan Lombok Post. Karena kehadirannya selalu ditunggu untuk menambah wawasan tentang ajaran agama Islam". ${ }^{18}$

Dan Mbak Ida selaku sekertaris Redaksi Juga mengatakan :

"Kehadiran rubrik itu ternyata mendaptkan respone fositip dari para pembaca lombok post terbukti dia bisa menjaga eksitensinya danselalu rutin di terbitkan dari tahun 2008 sampai saat ini, dan kurang lebih 10 tahun dan itu menandakan bahwasannya para pembaca cukup memberikan perhatian khusus untuk rubrik ini”. ${ }^{19}$

Pak H. Hammaluddin selaku sebagai wartawan senior Juga Mengatakan :

"Tujuannya itu lah yang saya jelaskan di tadi untuk keseimbangan pemberitaan, jangan hanya sifatnya prontal tapi media penyejukan

18 Pak Joni Marthadinata Dewan Redaksi Lombok Post(Wawancara Tanggal 15 Mei 2018).

19 Mbak Ida sekertaris Redaksi (Wawancara Tanggal 14 Mei 2018). medianya juga perlu ketika itu ,kesepakatan tim redaksi waktu mengambil sikap melalui rapat redaksi kalau gak salah waktu itu akhirnya di adakan dialog Jum'at dan kontennya ya itu, pesanpesan kepada masyarakat yang lagi boming di masyarakat saat itu dan ada kaitannya dengan khutbah-khutabah setiap Jum'at isinya juga macam-macam dah kontennya yang berkaitan dengan dakwah yang artinya untuk memberikan kesejukan moral terhadap masyarakat , dan sekitar 2008 itu akhirnya berlanjut- berlanjut dan itu tujuannya dialog jummat itu termasuk lah salah satu visi dan misinyalah. ${ }^{20}$

Rubrik Dialog Jum'at Di isi Hingga Saat ini karena Isinya yang tidak Monoton seperti yang di jelaskan oleh Pak Joni Marthadinata mengatakan :

"Alasan yang paling sering mengemuka karena rubrik Dialog Jumat sangat informatif dan edukatif. Topik bahasannya juga tidak monoton. Apa yang tidak didapatkan pembaca/ pelanggan di bangku sekolah/ kuliah, sering kali bisa didapatkan melalui Rubrik Dialog Jumat.

20 Pak Hamaluddin Wartawan Senior Lombok Post(Wawancara Tanggal 13 Mei 2018). 
Selain itu, posisi pengasuh TGH Shafwan Hakim yang sangat netral (di bidang politik). Pimpinan Ponpes Nurul Hakim Kediri ini tidak pernah memihak pada satu kelompok saja. Sehingga sosoknya diterima semua kalangan. ${ }^{21}$

Sama Halnya dengan yang di jelaskan oleh pak Hamaluddin yang mengatakan bahwa rubrik itu sangat bemanfaat untuk pembaca :

"Salah satu alasan mereka menurut saya adalah karena pesan moralnya sangat bagus rubrik tentang keimanan dan ketaqwaan terhadap ketuhanan dan sangat baik mamfaatnya untuk kita semua sehingga melalui dialog Jum'at itu kita mengetahui tentang apa sisi kelemahan kita sebagai umat apa yang belum kita pahami melalui rubrik dialog Jum”at. " 22

Rubrik tersebut dapat menjaga eksitensinya dalam menerbitkan Berita-beritanya dari tahun ke tahun dan terbukti sampai sekarang rubrik itu tetap masih hingga saat ini dan mendapatkan perhatian dari para

21 Pak Joni Marthadinata Dewan Redaksi Lombok Post(Wawancara Tanggal 15 Mei 2018).

22 Pak Hamaluddin Wartawan Senior Lombok Post(Wawancara Tanggal 13 Mei 2018). pembaca seperti yang di katakan oleh Mbak ida juga :

"Kehadiran rubrik itu ternyata mendapatkan respon positif dari para pembaca lombok post terbukti dia bisa menjaga eksitensinya dan selalu rutin di terbitkan dari tahun 2008 sampai saat ini, dan kurang lebih 10 tahun dan itu menandakan bahwasannya para pembaca cukup memberikan perhatian khusus untuk rubrik ini.” 23

Kemudian Pak Ikhiluddin selaku sebagai wartawan senior juga mengatakan :

“ yang jelas sih itu supaya ada ruang untuk pembaca gitu yang pengen tau tentang topik-topik Islam, kemudian hari Jum'at juga kan hari untuk beribadah yang akhirnya di fasilitasi rubrik khusus dialog Jum'at itu, nah ini jadi sebenarnya untuk keseimbangan lah ada bacaanbacanumum, berita-beritaumum dan ada topiknya yang agama. Makanya khirnya dulu di utuslah Tuan Guru Safwan Hakim dari pertama sampai sekarang itu dia waktu itu kan dulu Tuan Guru Safwan Hakim sedang menjabat sebagi ketua forum pimpinan

23 Mbak Ida Sekertaris Redaksi (Wawancara Tanggal 14 Mei 2018). 
pondok pesantren diNTB jadi di pilihlah beliau. ${ }^{24}$

Dari penjelasan pak joni marthadinata yang mengatakan bahwa tidak hanya pelanggan yang bergama Islam saja yang membaca tetapi ada juga pembaca yang non Islam. :

"Pelanggan Rubrik Dialog Jumat adalah semua pelanggan Lombok Post, terutama yang beragama Islam. Bahkan, rubrik ini juga dibaca oleh pelanggan maupun non pelanggan yang beragama selain Islam."

Waktu itu koran satu satunya di NTB ialah lombok post dan pada saat pula Koran Lombok Post menjadi salah satu koran terpopuler di kalangan masyarakat seperti yang di katakan oleh pak Hamaluddin :

"Ketika itu lombok post sedang boming ketika itu karena satusatunya koran tersebesar di ntb waktu itu gak ada suara ntb, radar lombok, yang ada hanya ketika itu Bali post, jadi pelangnnya dari tingkat kalangan pesantren, ada sekolah semua madrasah juga berlangganan ada instansi pemerintah dan pelanggan umum lainnya."

24 Pak Ikhliluddin Wartawan Senior (Wawancara Tanggal 17 Mei 2018).
Tetapi berbeda halnya dengan mbak Bq. Farida selaku sekertaris Redaksi yang mengatakan :

"Secara spesifik memang kami tidakmemilikidataberapa persen efek penambahan pelanggan baru dengan kehadiran rubrik itu tapi secara tidak langsung eeee kami juga membuka ruang kritik dan saran untuk masyarakat , dan sejauh ini ruang saran yang di berikan masyarakat memberikan apresiasi terhadap kehadiran rubrik tersebut dan naaah untuk apa namanya, dan para pelanggan atau pelanggan kami memang sejauh ini selalu memberikan masukan soal konten yang di sajikan di rubrik itu ternyata sesuai dengan isu-isu kekinian jadi memang pengasuh halaman yaitu TGH Safwan Hakim begitu luas membaca kondisi sosial di masyarakat jadi beliau menuangkan halhal yang menyangkut agama yang terjadi saat ini dituangkan di rubrik sihingga masyarakat bisa mengupdate masalah -masalah ke agamaan di rubrik itu sehingga tidak ada istilah jika rubrik itu hanya rubrik yang sudah ketinggalan zaman atau hal sebagainya karena konten-konten yang di sajikan 
memang di sesuaikan dengan problemmatika yang terjadi saat ini dan di masa ini." 25

Dialog Jum'at ternyata mempunyai daya tarik yang sangat besar dalam perusahaan dan rubrik tersebut salah satu menjadi daya tarik pasar dan pengaruh yang di dapatkan oleh perusahaan sangat baik karena konten dakwahnya di sesuaikan dengan penomenapenomena yang terjadi saat ini, seperti yang di jelaskan oleh pak H.Hamalddin selaku mengatakan:

"Eeee sangat berpengaruh ya setelah adanya rubrik itu yang di isi oleh para tokohtokoh agama atau tuan guru ada peningkatan oplah di situ karena kalanagan pesantren ya yayasan-yayasan pendidikakn itu mulai berlangganan koran yang awalnya merkea pesimis ragu hanya konten berita itu di isi kriminal, politik, jenuh mereka kan , dengan adanya dialog Jum'at tersebut mereka tertarik karena itu menjadi bahan kliping mereka untuk di kliping jadi bahan sosialisasi mereka juga untuk santri-santri di sekolah , apalagi yang isi itu tokoh-tokoh agama yang mempunyai pondok

25 Mbak Ida Sekertaris Redaksi (Wawancara Tanggal 14 Mei 2018). pesantren ya, ketika tuan guru muhlisi ibrahim , ada juga yang dari lombok timur juga Ust .Husan dulu kita suruh isi itu, tapi mereka secara bergiliran kan, misalnya dalam waktu 1 bulan 2 bulan nanti pindah lagi, itu agar masyarakat tidak jenuh sehingga dialog Jum'at itu di isi oleh berbagai kalangan , oleh kalangan NU, NW dan Muhammadiyah gito. " ${ }^{26}$

Dalam pembuatan Dialog jumat tersebut jusru ada terobosan baru yang di lakukan oleh perusahaan atau Tim Redaksi yaitu dengan merefres Rubrik yang lama menjadi dalam hal ini juga dijelakan oleh pak Joni Marthadinata selaku menjabat sebagai Pemimpin Reddaksi yang mengatakan:

"Keberadaan Rubrik Dialog
Jumat tentu menjadi "warna"
atau pembeda tersendiri di
halaman Koran Lombok Post.
Dari sisi Redaksi, banyak elemen
dan terobosan-terobosan baru
yang dilakukan Lombok Post
untuk terus meningkatkan oplah
(jumlah pelanggan). Untuk
memenuhi permintaan pasar,
beberapa rubrik yang sudah
"usang" diganti dengan rubrik

26 Pak Hamaluddin Wartawan Senior Lombok Post(Wawancara Tanggal 13 Mei 2018). 
baru yang lebih fresh dan menjadi kebutuhan pembaca (pelanggan). Namun beberapa rubrik lama juga tetap dipertahankan. Salah satunya Rubrik Dialog Jumat. ${ }^{27}$

Kemudian d jelaskan lagi oleh pak Ikhliluddin selaku sebagai mengatakan :

"Kalausayasihkalausyliat-liatdari spesifik yah untuk peningkatan oplah yah, maksdunya dari segi jumalah koran yang di cetak iya memang tidak keliatan yah tetapi dari sisi pembaca iya mungki bisa saja bertambah itu karena belum tentu orang yang baca koran itu membeli koran karena orang yang baca koran itu tidakbisa jadi ukurannya, jika pembacanya bertambah otomatis oplah koran itu akan bertambah karena ini model masyarkat kita di NTB yang minat bacanya masih rendah begitupun juga dengan minat beli masih berkurang. "

Sesuai dengan visi dan misi Lombok Post yang ingin mencerdaskan kehidupan bangsa, lombok post memilih akhirnya memilih Rubrik dialog Jum'at sebagai Kolom yang khusus mengisi konten-konten dakwah agar dapat menyeimbangkan berita-berita

27 Pak Joni Marthadinata Dewan Redaksi Lombok Post(Wawancara Tanggal 15 Mei 2018). umum dengan umum sekalgus mendapatkan pahala Dari tuhan yang maha esa, seperti yang di jelaskan oleh pak Joni Marthadinata selaku Pemimpin Redaksi yanng mengatakan :

"Sesuai visi perusahan Lombok Post: Mengamalkan Pancasila dan Mencerdaskan Bangsa. Di sisi lain, SDM Lombok Post, terutama di Bagian Redaksi juga ingin mendapatkan pahala dengan menerbitkan Rubrik Dialog Jumat.

Sama halnya yang dijelaskan oleh mbak Bq. Farida selaku menjabat sebgai sekertaris redaksi yang menatakan bahwa ingin memberikan :

"Secara garisbesar visi dan misi melalui adanya rubrik itu kami ingin menonjolkan apa, wajah Lombok Barat, wajah NTB sebagai Provinsi dengan mayoritas muslim terdepan ,dan kami ingin memberikan ruang ke masyarakat untuk mendapatkan penyecarahan dari sisi agama, jadi selain informasi kami juga memiliki tanggung jawab moral dalam perusaahan kepada masyarakat, jadi kami bertanggung jawab selain 
memberikan dari sisi agama nya dengan memberikan pencerahan siraman rohani.$^{28}$

Kemudian di jelaskan oleh pak Hamaluddin mengatakan :

"iya itu untuk kesejukan moral terhadap masyarakat. “29

Dengan menjga konten-konten dakwahnya Rubrik Dialog Jum'at di kemas sesuai dengan kebetuhan masayrakat dan juga lebih pleksibel mambahas pesoalan-persoaln agama yang memang menjadi perhatian masyarakat saat ini seperti yang di jelaskan oleh mbak Bq. Farida selaku sekertaris redaksi mengatakan :

"Terus bagaimaan cara kami mempertahankan rubrik ini tetap ada sampai saat ini ya dengan menjaga konren-konten yang di sajikan di rubrik itu agar sesuai dengan kebutuhan masyarakat jadi buka hanya membahas soal akidah atau soal-soal keagamaan yang memang sifatnya bagu tetapi kami juga lebih pleksibel mambahas pesoalan-persoaln agama yang memang menjadi perhatian masyarakat saat ini , seperti itu, jadi sehingga selalu

28 Mbak Ida Sekertaris Redaksi (Wawancara Tanggal 14 Mei 2018).

29 Pak Hamaluddin Wartawan Senior Lombok Post(Wawancara Tanggal 13 Mei 2018). up to date apa yang di sajikan di rubrik tersebut. ${ }^{30}$

\section{B. Isi Pesan Dakwah dalam} Rubrik Dialog Jum'at Koran Lombok Post

1. Pesan dakwah Dalam Rubrik Dialog Jum'atKoran Lombok Post

a. Pesan Akhlak (Jangan pernah Berhenti Mencari Ilmu)

Dalam Rubrik Dialog Jum'at edisi 4 Aguatus Terdapat Pesanpesan Dakwah, Diantaranya, pada Paragraf pertama yang menjelaskan tentang mencari Hukum mencari Imam ke tempat lain

"Imam Ketempat lain tidaklah mengapa karena mencari Imam ke tempat Lain sama Halnya dengan mencari Ilmu dan bahkan di kategorikan sebagai seorang Musafir untuk mencari pemahamn terhadap Al Quranulkarim, serta mendengarkan suaranya yang sangat bagus dan musafir dalam mencari Ilmu sangat di anjurkan. 31

b. Tawaddu

30 Mbak Ida Sekertaris Redaksi (Wawancara Tanggal 14 Mei 2018).

31 Koran Lombok Post...,7 
Dalam edisi 11 Agustus 2017 TGH. Safwan Hakim menjelaskan tentang Kita Harus Beriman dan di Barengi Amal Saleh yang di Kutip dari Hadist Rasulullah SAW .

"Amal yang paling utama adalah salat lima waktu dan akhlak yang terbaik adalah tawwaddu,"

c. Sedekah atau Amal saleh

Dan di jelaskan Kembali oleh TGH, Safwan Hakim

"Antara akhlak yang mulia itu ialah tawaddu. Karena tawaddu itu merupakan akhlak yang utama, ${ }^{32}$

d. Berlaku lemah lembut kepada yang lebih kecil dan meghormati yang lebih tua.

Dalam Edisi 18 Agustus 2017 juga menjelaskan tentang pesan Akhlak yaitu dalam paragraf ke 4 yang menjelaskan tentang

"Hormati yang besar dan cintai yang kecil, ${ }^{33}$

e. Pesan Sosial yaitu siap Berkorban Demi Orang Lain

Paragraf ke 5 Edisi 25 Agustus 2017 menjelaskan tentang pesan Akhlak yaitu:
"Berkorban untuk orang lain dan mnegorbankan kepentingan sendiri adalah sifat yang baik dan terpuji, karena dengan demikian tidak akan ada orang yang kehilangan haknya-haknya, tetai justru ia akan mendapatkan sesuatu yang sebenarnya bukan haknya tanpa merugikan orang lain, atau menyakiti perasaannya. ${ }^{34}$

f. Pesan SyariahatauPesan Tauhid yaitu Taat Kepada Allah

Pada Edisi 15 September 2017 TGH. Safwan menjelaskan tidak hanya pesan Akhlak saja tetapi disinijuga menjelaskan tentang pesan syariah, yaitu pada paragraf ke 3 :

"Dengan berzikir kepada Allah akan mengingat kita, memberi pertolongan dan mendapatkan ganjaran darinya, dan kita menjadi dekat dengan Allah SWT. Dan apabila sesorang telah dekat dengan Allah maka ia akan di sayang, permohonannya akan selalu di kabulkan, serta tidak di ragukan kelak ia akan di masukkan ke dalam syurganya."

g. Menjadikan kepribadian menjadi lebih baik terhadap

32 Koran Lombok Post...,1.6

33 Koran Lombok Post..., 6

34 Koran Lombok Post...,7 
nasib umat Islam di bumi manapun.

h. Hijrah (Dari Yang Buruk ke Yang lebih Baik)

i. Bertanggung Jawab Pesan Tentang Kelebihan Puasa Sunnah Asyura

Di jelaskan kembali dalam edisi 29 September 2017 dalam hal ini TGH.Safwan mengutip dari sebuah hadist Rasulullah saw yang di riwayatkan oleh Bukhori dan Muslim, yang mengatakan bahwa :

\section{"Dianjurkan}

untuk mempuasakan pada tanggal sembilan pada bulan Asyura " 35

\section{Penutup}

Rubrik Dialog Jum'atKoran Lombok dan Isi Pesan Dakwah dalam Rubrik Dialog Jum'atKoran Lombok Post merupakan kolom khusus yang terdapat di koran Lombok Post yang di terbitkan pertama kali pada tahun 1996 dan dipublikasikan di tahun 2008, Dan H. Munawarunlah yang pertama kali mempunyai ide terhadap pembuatan Rubrik tersebut dan di sepakati oleh Tim Redaksi untuk memberikan sajiansajian tentang ajaran Islam, Rubrik dialog Jum'at di terbitkan supaya ada keseimbangan antara kajian umum dan agama, tidak hanya memberikan informasi umum tetapi juga memerikan informasi seputar agama Islam.

Dan harus diakui pengetahuan tentang agama terutama yang berkaitan dengan kehidupan sehari-hari sangat dibutuhkan oleh masyrakat terutama masyraakat muslim di NTB. Dan rubrik dialog Jum'atkoran Lombok Post pun memilik peminat yang banyak mengingat koran Lombok Post merupakan satu-satunya koran yang memiliki kolom khusus untuk rubrik dialog Jum'at,dan teknik penyusunan pesantermasuk dalam teknik penyususnan pesan yang bersifat informatif dan persuasif.

Adapunisi pesan dakwah pada rubrik dialog Jum'atkoran Lombok Post yang mengandung pesan:Jangan pernah berhenti mencari ilmu, berakhlak,bersedekah, berlaku lemah lembut kepada yang lebih kecil dan megeormati yang lebih tua, pesansosialyangselalusiapberkorban demi orang lain, taat kepada Allah, menjadikan kepribadian menjadi lebih baik terhadap nasib umat Islam di bumi manapun, kuat lemahnya iman terkait dengan kepedulian terhadap penderitaan orang-orang beriman,hijrah, bertanggung jawab pesan tentang kelebihan puasa sunnah asyura.

35 Koran Lombok Post..., 7 
Daftar Pustaka

Ambar, "Analisis Wacana Kritis, Pendekatan Konsep"dalam http: / / pakarkomunikasi.com

Ikram Maifandi, "Analisi Wacana" dalam di akses pada tanggal 19 april 2018

Khurin'in,"Media Sebagai Alat Dakwah". Dalam digilib.uinsby. ac.id.bab\%202.pdf, ḍ2013

Koran Lombok Post, Dalam Rubrik Dialog Jum'at edisi 4 Agustus

Morisson, Teori Komunikasi Individu Hingga Massa, (Jakarta, 2013)
Mursito BM, Jurnalistik Komprehensif, (Jakarta: Literate, 2013)

Nurudin, Jurnalisme Masa Kini,(Jakarta: RajawaliPers, 2009)

$\mathrm{Si}$ Manis, "Analis Wacana" dalamhttp: / / www.pelajaran. co.idldi akses pada tanggal 19 April 2018

Zikri, Fachrul Nurhadi, Teori-Teori Komunikasi Dalm Perspektif Penelitian Kualitatif,(Bogor : Ghalia Indonesia, 2015) 